\title{
Placentas and Newborns of Patients Suffering from High Blood Pressure in University Hospital of Brazzaville
}

\author{
Cautaire Itoua ${ }^{1}$, Jules Cesar Mokoko¹, Neli Yvette Ngakengni², \\ Mpianuelly Samantha Bialay Potokoue ${ }^{1}$, Levy Max Emmery Eouani ${ }^{3}$, Abdel Salam Bachir ${ }^{1}$, \\ Jean Felix Peko', Leon Herve Iloki' ${ }^{1}$
}

\footnotetext{
${ }^{1}$ Gynecology and Obstetric Department, University Hospital of Brazzaville, Brazzaville, Congo

${ }^{2}$ Neonatology Department, University Hospital of Brazzaville, Brazzaville, Congo

${ }^{3}$ Gynecology and Obstetrics Department, Hôpital général de Loandjili, Pointe Noire, Congo

${ }^{4}$ Anatomy and Pathology Department, University Hospital of Brazzaville, Brazzaville, Congo

Email: *clautairei@yahoo.com
}

\begin{abstract}
How to cite this paper: Itoua, C., Mokoko, J.C., Ngakengni, N.Y., Potokoue, M.S.B., Eouani, L.M.E., Bachir, A.S., Peko, J.F. and Iloki, L.H. (2019) Placentas and Newborns of Patients Suffering from High Blood Pressure in University Hospital of Brazzaville. Open Journal of Obstetrics and $G y$ necology, 9, 649-655.

https://doi.org/10.4236/ojog.2019.95064
\end{abstract}

Received: February 18, 2019

Accepted: May 17, 2019

Published: May 20, 2019

Copyright $\odot 2019$ by author(s) and Scientific Research Publishing Inc. This work is licensed under the Creative Commons Attribution International License (CC BY 4.0).

http://creativecommons.org/licenses/by/4.0/

\section{cc) (i) Open Access}

\begin{abstract}
Objective: To analyze placentas and newborns of patients with high blood pressure (HBP). Materials and Methods: Case-control study conducted from 1 January to 31 October 2017 in University Hospital of Brazzaville (birth room, anatomy and pathology laboratory) and Faculty of Health Sciences of Brazzaville (laboratory of anatomy and organogenesis). It concerned 40 placentas freshly delivered and newborns of patients with HBP compared to 40 placentas and newborns of patients without HBP. The variables analyzed were related to mothers, placentas and the newborns. Results: The patients were similar in age $(26.9 \pm 1.2$ years VS $26.5 \pm 1.1$ years, $\mathrm{p}=0.17)$ and parity $(1.26 \pm 0.7$ VS $1.61 \pm 0.3, p=0.26)$. The type of hypertension in the cases was dominated by pre-eclampsia (68\%). A significant reduction in placental measurements was more observed in case of HBP: weight ( $431 \pm 37$ g VS 503 $\pm 26 \mathrm{~g}, \mathrm{p}<0.05)$, diameter $(17.40 \pm 1.2 \mathrm{~cm}$ VS $19.25 \pm 1 \mathrm{~cm}, \mathrm{p}<0.05)$, and area $\left(239.82 \pm 15.7 \mathrm{~cm}^{2}\right.$ VS $\left.292.1 \pm 22.2 \mathrm{~cm}^{2}, \mathrm{p}<0.05\right)$. The macroscopic lesions were calcifications $(75 \%$ VS $43.8 \%, \mathrm{p}<0.05)$ and the retro placental hematoma cup (18.8\%) among the cases. Microscopic lesions were more observed in hypertensives: infarction $(68.8 \%$ VS $18.8 \%, \mathrm{p}=0.004)$ and endarteritis $(93.8 \%$ VS $12.5 \%, p<0.05)$. The characteristics of newborns were significantly different between the two populations: prematurity (34.3\% VS 9.3\%, p < 0.05), mean weight $(2577 \pm 102 \mathrm{~g}$ VS $3060 \pm 109 \mathrm{~g}, \mathrm{p}<0.05)$, the average APGAR score (6.7 \pm 1.6 VS $7.8 \pm 0.9, \mathrm{p}<0.05)$, and the neonatal transfer $(18.7 \%$ VS $3.1 \%$; $p$ $<0.05$ ). Conclusion: High blood pressure affects the placenta and the newborn. The placenta deserves to be systematically examined.
\end{abstract}




\section{Keywords}

High Blood Pressure, Placenta, Newborn, Brazzaville, Congo

\section{Introduction}

As a mother-fetus interface, the placenta ensures the gaseous and nutritive exchanges required for growth and fetal development. Simple anatomical waste having accomplished its work of nutrition in our societies is endowed with a mystical power protector. It is often burned, thrown, or buried [1] [2]. Its development undergoes continuous morphological and functional changes, and it interacts with the mother and the fetus [1] [2]. Examination of the placenta is not systematic in the context of high blood pressure in our hospital [3]. The present work aims to contribute to the management of patients with hypertension by analyzing placenta.

\section{Patients and Methods}

This is a case-control study conducted from 1 January to 31 October 2017 in the University Hospital of Brazzaville (birth room, Laboratory of Pathological and Anatomy) and in the Faculty Health Sciences (laboratory of Anatomy and Organogenesis). The study concerned 40 placentas delivered and neonates of hypertensive patients compared to 40 of non-hypertensive patients. Placentas and neonates born from fetal pregnancies with at least 28 weeks of amenorrhoea with or without hypertension were included in the study. Incomplete, abnormally inserted or adhered placentas and scar uteri of both populations were not taken into account. Recruitment of placentas and newborns was performed by random draw according to the ratio of placenta and neonate of a hypertensive to that of a non-hypertensive birth that followed directly.

The procedure for examining the placenta was as follows:

- Immediate collection of the placenta and transport to the laboratory of anatomy and organogenesis for a morphological study

- Wash the placental vascular network with physiological saline to get rid of blood clots and staining the umbilical vessels for a reconstitution of the placental vascular tree;

- Macroscopic examination of the placenta after immersion of the placenta in $10 \%$ formalin and dissection by $5 \mathrm{~mm}$ serial sections;

- Histological examination after identification, dehydration, paraffin embedding and hematoxylin-eosin staining.

The colored cups were finally protected by a glass slide mounted with the balm of canapa.

The variables studied were maternal (age, parity and type of arterial hypertension), placental (shape, measurements, constitution, vascularization, and microscopy), and neonatal (term, weight, Apgar score) and transfer to neonatology). 
The comparison of percentages used the Chi-square test and that of the averages the t-Student test. The value of $\mathrm{p}<0.05$ was considered as a threshold of statistical significance.

Cette étude a reçu l'accord du comité d'éthique.

Conflit d'intêret aucun.

\section{Results}

Patients were similar in age $(26.9 \pm 1.2$ years VS $26.5 \pm 1.1$ years, $\mathrm{p}=0.17)$ and parity $(1.26 \pm 0.7 \mathrm{VS} 1,61 \pm 0.3, \mathrm{p}=0.26)$. The type of hypertension in the cases returned to pre-eclampsia (68\%), pregnancy (20\%), and chronic (12\%).

The form of the placentas with HBP was similar to that of non HBP patients: circular (65.5\% VS 67\%, $\mathrm{p}=0.65)$ and oval (34.5\% VS 33\%, $\mathrm{p}=0.65)$.

A significant reduction in placenta measurements was observed more in hypertensives weight (431 \pm 37 g VS $503 \pm 26 \mathrm{~g}, \mathrm{p}<0,05)$, diameter $(17.40 \pm 1.2$ $\mathrm{cm}$ VS $19.25 \pm 1 \mathrm{~cm}, \mathrm{p}<0.05)$, and area $\left(239.82 \pm 15.7 \mathrm{~cm}^{2}\right.$ VS $292.1 \pm 22.2 \mathrm{~cm}^{2}$, $\mathrm{p}<0.05)$ as reported in Table 1 . The umbilical cord of different term $(37.07 \% \pm$ $2.19 \%$ VS $38.41 \% \pm 0.93 \%, p=0.001)$.

Macroscopic placental lesions (Table 2) were represented by calcifications (75\% VS 43.8\%, p < 0.05) and the retro placental hematoma cup (18.8\%) among the cases. Microscopic lesions were more observed in hypertensives: infarction (68.8\% VS $18.8 \%, \mathrm{p}=0.004)$ and endarteritis $(93.8 \%$ VS $12.5 \%, \mathrm{p}<0.05)$ and the cup of retro placental hematoma in cases. Microscopic lesions of villous hyalinosis (Picture 1) and endarteritis were more observed in hypertensive patients. Other microscopic lesions such as villous haemangioma (Picture 2) and chondroid metaplasia (Picture 3) were observed exclusively in hypertensive patients.

The characteristics of the newborns were different between the two populations: the term, the weight, the APGAR score, and the transfer to neonatology (Table 3).

\section{Discussion}

The retrospective nature of the study did not allow us to establish the link between the types of hypertension, placental involvement on the one hand and neonatal repercussions on the other.

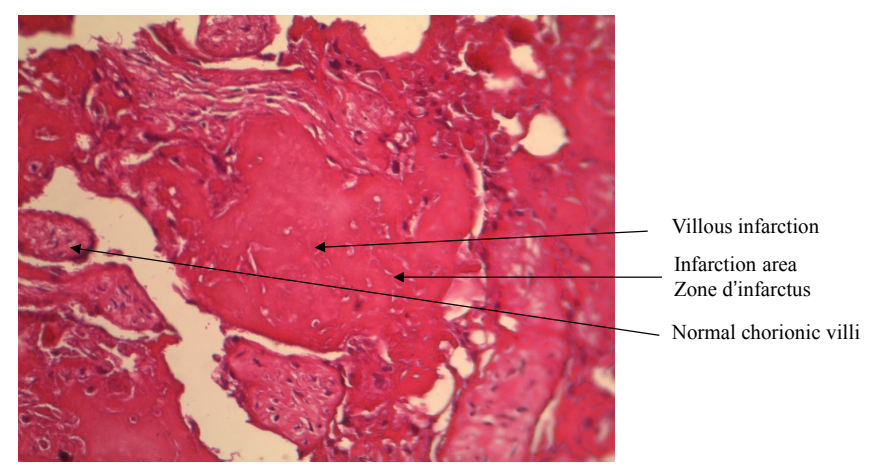

Picture 1. (HE) Gx300 Villous hyalinosis. 


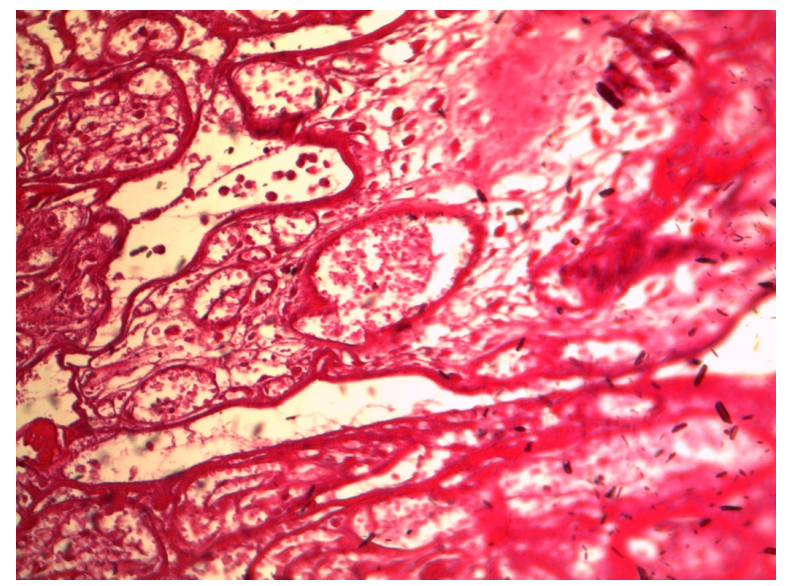

Picture 2. (HE) Gx300 Villous Hemangioma.

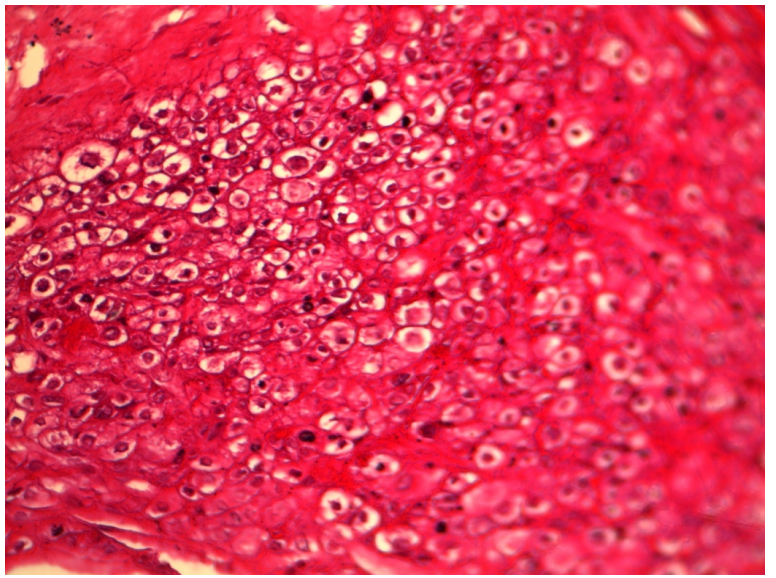

Picture 3. (HE) Gx300 Chondroid Metaplasia.

Table 1. Placental form and measurement.

\begin{tabular}{cccc}
\hline & $\begin{array}{c}\text { High blood pressure } \\
\text { Averages } \pm \mathrm{SD}\end{array}$ & $\begin{array}{c}\text { Indicators } \\
\text { Averages } \pm \mathrm{SD}\end{array}$ & P-value \\
\hline Weight & $431 \pm 37 \mathrm{~g}$ & $503 \pm 26 \mathrm{~g}$ & $\mathrm{p}<0.05$ \\
Diameter & $17.4 \pm 1.2 \mathrm{~cm}$ & $19.2 \pm 1.5 \mathrm{~cm}$ & $\mathrm{p}<0.05$ \\
Thickness & $1.8 \pm 0.2 \mathrm{~cm}$ & $2.2 \pm 0.2 \mathrm{~cm}$ & $\mathrm{p}<0.05$ \\
Area & $239.8 \pm 15.7 \mathrm{~cm}^{2}$ & $292.1 \pm 22.2 \mathrm{~cm}^{2}$ & $\mathrm{p}<0.05$ \\
Volume & $427.4 \pm 33.3 \mathrm{~cm}^{3}$ & $649.9 \pm 50.2 \mathrm{~cm}^{3}$ & $\mathrm{p}<0.05$ \\
Number of cotyledons & $15.9 \pm 0.7$ & $19.5 \pm 1.6$ & $\mathrm{p}<0.05$ \\
\hline
\end{tabular}

Table 2. Placental abnormalities.

\begin{tabular}{cccc}
\hline & $\begin{array}{c}\text { High Blood Pressure } \\
\text { Effective (\%) }\end{array}$ & $\begin{array}{c}\text { Indicators } \\
\text { Effective (\%) }\end{array}$ & P-value \\
\hline Calcifications & $24(75)$ & $14(43.7)$ & 0.01 \\
Cup & 18.8 & 0 & \\
Infarct & $11(68.8)$ & $3(18.8)$ & 0.004 \\
Endartrite & $15(93.8)$ & $2(12.5)$ & 0.0001 \\
Villous hemangioma & $16(50)$ & & \\
Chondroid metaplasia & $3(9.3)$ & $10(62.5)$ & 0.29 \\
Anastomosis of Hyrtl & $7(43.7)$ & & \\
\hline
\end{tabular}


Table 3. Characteristics of newborns.

\begin{tabular}{cccc}
\hline & High blood pressure & Indicators & P-value \\
\hline $\begin{array}{c}\text { Term } \\
\text { (average } \pm \text { SD) } \\
\text { Weight } \\
\text { (average } \pm \text { SD) }\end{array}$ & $37 \pm 2.1 \mathrm{SA}$ & $38.4 \pm 0.9 \mathrm{SA}$ & $\mathrm{p}<0.05$ \\
$\begin{array}{c}\text { Apgar } \\
\text { (average } \pm \text { SD) } \\
\text { IUGR }\end{array}$ & $6.7 \pm 1.6$ & $3060 \pm 109 \mathrm{~g}$ & $\mathrm{p}<0.05$ \\
$\begin{array}{c}\text { Fetal death } \\
\text { Neonatal transfer }\end{array}$ & $16(50)$ & $7.8 \pm 0.9$ & 0.001 \\
\hline
\end{tabular}

IUGR: intra uterine growth retardation.

However, like Segupta [4] in Bangladesh, we did not find any difference between the ovular and circular forms of placentas of hypertensives and non-hypertensives.

On the other hand arterial hypertension has led to an overall reduction in placental measurements including weight, diameter, surface, thickness and volume. Similar results have been reported by other authors [5] [6] [7] [8] [9] who reveal that the pathological process is related to vascular involvement, which interferes with normal placental growth by reducing intakes.

Thus macroscopically abnormalities of the placental and funicular vascular architecture observed would promote vascular rupture and could explain the existence of the cup of retro placental hematoma (RPH) exclusively in the hypertensive population. Our results corroborate those of Pasricha [10] who found $\mathrm{RPH}$ in 33\% of placentas only in hypertensive patients.

In contrast, thrombotic occlusion of placental uterine vessels may occur and explain the more frequent placental infarction in hypertensive patients. These results are similar to those of Udaina [11], who in 2004 reported $92.5 \%$ of placental infarction from hypertensives against $29 \%$, and emphasized that an attack greater than $5 \%$ of the placental surface is considered as being pathological.

Similarly the rate of increased placental calcifications in hypertensives was reported by Pasricha [10] in 70\% of hypertensive placentas compared to $10 \%$ in the control group. These results suggest that HBP by its perfusion abnormalities would cause placental stress at the origin of early maturation.

Microscopically, endarteritis, which is the inflammation of the inner layer of the artery, was found mainly in the HBP group. These results are close to those of the literature [11] [12] [13] [14]. The consequences that result from this inflammation are either obliteration of the vascular lumen or clot formation due to the modification of the endothelial structure.

The various macroscopic and microscopic lesions resulted in an alteration of the placental exchange functions that may resonate on the fetus. Thus our study revealed a prevalence of hypotrophy close to that of Prabhjot [5], who found $44 \%$ of hypotrophy exclusively in pre-eclampsia. Hypertensive newborns had a 
poor Apgar rating following perinatal asphyxia with a higher neonatal transfer.

\section{Conclusion}

This work confirmed the repercussions of high blood pressure on the placenta and the newborn. Examination of the placenta is therefore of interest in understanding perinatal pathology.

\section{Conflicts of Interest}

The authors declare no conflicts of interest regarding the publication of this paper.

\section{References}

[1] Burdet, L.L., Epinay, M., Bornand, A., Pechere-Bertschi, A. and Ditishein, A. (2016) Le placenta: Nouvel organe cible de l'hypertension? Revue Médicale Suisse, 12, 1524-1528.

[2] Cunningham, F., Leveno, K. and Bloom, S. (2009) Pregnancy Hypertension. Williams Obstetrics. 23rd Edition, Vol. 34, McGraw Hill Medical, New York, 706-756.

[3] Itoua, C., Ngounda Monianga, A.S., Ellenga Mbolla, B.F., Mbemba Moutounou, G.M., Gombet Koulimaya, C.E., Gombet, T.R. and Iloki, L.H. (2013) Hypertension artérielle et grossesse: Epidémiologie et pronostic materno-fotal au Centre Hospitalier Universitaire de Brazzaville. Medecine d Afrique Noire, 60, 20-29.

[4] Segupta, K., Shamim, A. and Khandaker, A.R. (2009) Morphological Changes of Placenta in Preeclampsia. Bangladesh Journal of Anatomy, 7, 49-54. https://doi.org/10.3329/bja.v7i1.3026

[5] Prabhjot, K., Subhash, K. and Kuljit, S. (2013) Placental Weight, Birth Weight and Fetal Outcome in Preeclampsia and Normotensive Pregnancies. IJPAES, 3, 30-34.

[6] Priya, G., Bhavina, K. and Sundarapandian, S. (2012) Morphometric Study of Human Placenta in Preeclampsia Associated with Intrauterine Growth Retardation. International Journal of Pharma and Bio Sciences, 3, 471-475.

[7] Saurjyaranjan, D., Pradeep, K. and Sahadev, S. (2015) Morphological Study of Placenta in Pregnancy with Hypertension in Western Odisha. International Journal of Pharmaceutical Sciences Review and Research, 33, 74-78.

[8] Gyan, C.A., Pankaj, S. and Jai, P. (2015) Morphological Study of Placenta in Normal and Hypertensive Pregnancies. International Archives of Integrated Medicine, 2, 121-128.

[9] Abdul, H., Salma, F. and Asmat, K. (2012) Comparison of Placentae from Hypertension Associated Pregnancies and Normal Pregnancies. JLUMHS, 11, 1-6.

[10] Pasricha, N. (2012) Placental Morphology and Its Co-Relation with Foetal Outcome in Pregnancy-Induced Hypertension. International Journal of Basic and Applied Medical Sciences, 2, 120-125.

[11] Udainia, A., Bhagwat, S.S. and Mehta, C.D. (2004) Relation between Placental Surface Area, Infarction and Fetal Distress in Pregnancy Induced Hypertension with its Clinical Relevance. Journal of the Anatomical Society of India, 53, 27-30.

[12] Nahar, L., Nahar, K. and Hossain, M.I. (2015) Placental Changes in Pregnancy Induced Hypertension and its Impacts on Fetal Outcome. Mymensingh Medical Journal, 24, 9-17. 
[13] Majumdar, S., Dasgupta, H. and Bhartacharaya, K. (2005) A Study of Placenta in Normal and Hypertensive Pregnancies. Journal of the Anatomical Society of India, 54, 1-9.

[14] Londhe, P.S. and Mane, A.B. (2011) Morphometric Study of Placenta and its Correlation in Normal and Hypertensive Pregnancies. International Journal of Pharma and Bio Sciences, 2, 429-439. 